\title{
PERBEDAAN EFEKTIVITAS MASSAGE EFFLEURAGE DAN KOMPRES DINGIN TERHADAP NYERI PERSALINAN DI PUSKESMAS KABUPATEN PEKALONGAN
}

\author{
Wahyu Ersila' ${ }^{1)}$, Lia Dwi Prafitri ${ }^{2)}$, Nina Zuhana ${ }^{3)}$ \\ 1ersila.chila88@gmail.com, 22L02Prafitri@gmail.com, ${ }^{3}$ ninazuhana@gmail.com \\ ${ }^{1,2}$ Prodi S1 Fisioterapi STIKES Muhammadiyah Pekajangan Pekalongan \\ Jl Raya Ambokembang No.8 Pekalongan \\ ${ }^{3}$ Prodi D3 Kebidanan STIKES Muhammadiyah Pekajangan Pekalongan \\ Jl Raya Ambokembang No.8 Pekalongan
}

\begin{abstract}
Abstrak
Seorang wanita secara fisiologis akan mengalami kehamilan, persalinan dan menjalani masa nifasnya. Beberapa wanita yang pernah melahirkanpun terkadang memiliki perasaan trauma atau khawatir terhadap rasa nyeri yang timbul pada saat persalinan, nyeri persalinan dianggap nyeri yang paling menyakitkan oleh ibu-ibu yang baru pertama kali mengalaminya. Penanganan nyeri non farmakologis dapat diterapkan untuk membantu mengurangi nyeri persalinan, salah satunya dengan melakukan massage effleurage dan kompres dingin. Tujuan penelitian ini untuk mengetahui perbedaan efektivitas massage effelurage dan kompres dingin terhadap nyeri persalinan. Jenis penelitian Quasi eksperimen. Instrumen penelitian menggunakan Numeral Rating Scale (NRS) pada 30 responden terdiri dari 15 responden kelompok massage effleurage dan 15 kelompok kompres dingin. Analisa data menggunakan uji Mann Whitney. Hasil terdapat perbedaan massage effelurage dan kompres dingin terhadap nyeri persalinan dengan nilai $p$ 0,001 (<0,05)sehingga dapat disimpulkan massage effleurage lebih efektif untuk menurunkan nyeri persalinan. Saran hendaknya bidan dapat mensosialisasikan dan mengaplikasikan massage effelurage sebagai metode non farmakologi untuk mengurangi nyeri persalinan
\end{abstract}

Kata kunci: Massage effleurage,kompres dingin,nyeri persalinan

\begin{abstract}
A woman physiologically will experience pregnancy, childbirth and the puerperium. Some women who have given birth sometimes have feelings of trauma or worry about the pain that arises during labor, labor pain is considered to be the most painful pain by mothers who have experienced it for the first time. Non-pharmacological pain management can be applied to help reduce labor pain, one of which is to do effleurage massage and cold compresses. The purpose of this study was to determine the difference in effectiveness of effelurage massage and cold compresses against labor pain. This type of research is Quasi experiment. The research instrument used the Numeral Rating Scale (NRS) in 30 respondents consisting of 15 respondents in the group of effleurage massage and 15 groups of cold compresses. Data analysis using the Mann Whitney test. The results showed that there were differences in effelurage massage and cold compress on labor pain with a palue of 0.001 (<0.05) so that it could be concluded that effleurage massage was more effective in reducing labor pain. Suggestions should midwives be able to socialize and apply effelurage massage as a non-pharmacological method to reduce labor pain.
\end{abstract}

Keywords: Effleurage massage, cold compress, labor pain

\section{Pendahuluan}

Derajat Kesehatan masyarakat dapat di nilai dari Angka Kematian Ibu (AKI) yang dilihat dari sisi aksesbilitas maupun kualitas terhadap layanan kesehatan. Survei Demografi
Kesehatan Indonesia (SDKI) menujukkan AKI sebesar 359 per 100.000 kelahiran hidup pada tahun 2012. Pada tahun 2015 hasil Survei Penduduk Antar Sensus (SUPAS) AKI mengalami penurunan menjadi 
305 per 100.000 kelahiran hidup ${ }^{[1]}$. Tiga faktor utama penyebab utama Kematian Ibu meliputi perdarahan (28\%), eklamsia (24\%) dan infeksi (11\%). Komplikasi yang terjadi pada saat persalinan dan setelah persalinan, serta pengetahuan ibu yang masih minim terkait dengan bahaya persalinan menjadi penyebab tingginya angka kematian $\mathrm{ibu}^{[2]}$.

World Health Organization (WHO) menyatakan bahwa 99\% tingginya AKI disebabkan masalah dalam persalinan atau kelahiran. Disamping faktor pengetahuan ibu yang masing minim mengenai komplikasi persalinan, kematian pada ibu bersalin dapat disebabkan karena adanya faktor 3 terlambat, yaitu terlambat mengambil keputusan dalam memberikan pertolongan ibu hamil dan melahirkan, terlambat membawa ke tempat pelayanan kesehatan, dan terlambatnya tenaga medis memberikan pertolongan ${ }^{[3]}$.

Persalinan merupakan suatu kondisi dimana leher rahim mengalami penipisan dan mulut rahim mengalami dilatasi yang diikuti oleh turunnya janin melalui jalan lahir kemudian disusul oleh kelahiran yaitu proses keluarnya hasil konsepsi (janin dan plasenta) dari rahim $^{[9]}$. Sebagian besar (90\%) ibu bersalin mengalami nyeri pada proses persalinannya $^{[5]}$. Kejadian nyeri pada 2.700 ibu bersalin, $15 \%$ mengalami nyeri ringan, $35 \%$ dengan nyeri sedang, 30\% dengan nyeri hebat dan $20 \%$ dengan nyeri sangat hebat. Secara fisiologis nyeri terjadi ketika otot-otot rahim saling berkontraksi sebagai upaya untuk membuka serviks dan mendorong kepala bayi ke arah panggul. Nyeri pada persalinan kala I merupakan proses yang terjadi secara fisiologis yang disebabkan oleh proses dilatasi serviks, hipoksia otot uterus saat kontraksi, iskemia korpus uteri dan peregangan segmen bawah rahim dan kompresi syaraf di serviks mengakibatkan impuls nyeri bertambah banyak ${ }^{[3]}$.

Seorang wanita akan mengalami kondisi yang fisiologis terkait dengan perkembangan hidupnya, diantaranya mengalami kehamilan, persalinan dan menjalani masa nifasnya. Kondisi tersebut tentunya untuk beberapa wanita dianggap hal yang menakutkan terutama bagi wanita yang belum pernah menjalani proses kehamilan atau persalinan sebelumnya. Beberapa wanita yang pernah melahirkanpun terkadang memiliki perasaan trauma atau khawatir terhadap rasa nyeri yang timbul pada saat persalinan, nyeri persalinan dianggap nyeri yang paling menyakitkan oleh ibu-ibu yang baru pertama kali mengalaminya ${ }^{[4]}$.

Penanganan nyeri dalam proses persalinan harus diperhatikan oleh pemberi asuhan pada masa persalinan. Kadangkala tenaga kesehatan dan ibu yang sedang dalam masa persalinan mengabaikan untuk menerapkan tehknik untuk memanage nyeri, terutama apabila rasa nyeri tersebut terasa pada bagian pinggang, sehingga ibu kemungkinan akan merasakan nyeri yang hebat pada masa persalinan kala I. Adanya rasa nyeri ini akan berdampak pada rasa trauma atau pengalaman persalinan yang buruk bahkan secara tidak langsung dapat menyebabkan post partum blues ${ }^{[5]}$.

Respon nyeri yang dialami oleh ibu primigravida dengan multigravida mengalami perbedaan yang signifikan, hal ini disebabkan pengalaman melahirkan sebelumnya memiliki pengaruh yang kuat terhadap respon nyeri pada ibu sudah pernah melahirkan. Ibu yang belum pernah melahirkan sebelumnya akan mengalami tingkat kecemasan dan ketakutan yang dapat menyebabkan stress dalam mengahadapi persalinannya. Dengan demikian diperlukan menejemen nyeri persalinan yang mampu menurunkan 
intensitas nyeri selama ibu dalam masa persalinan terutama ibu yang pertama kali bersalin ${ }^{[3]}$.

Beberapa metode alternatif yang ditawarkan untuk menurunkan nyeri pada persalinan diantaranya metode farmakologis (menggunakan obatobatan) dan non-farmakologis (secara tradisional). Metode farmakologis pengelolaannya dilakukan sebagian besar merupakan tindakan medis. Sedangkan pengelolaan metode nonfarmakologis dapat dilakukan oleh sebagian besar pemberi asuhan kesehatan (dokter, bidan, perawat) yang mungkin juga melibatkan keluarga ibu bersalin. Walaupun metode farmakologis lebih efektif dalam mengurangi nyeri persalinan, selain lebih mahal juga memiliki potensi kurang baik bagi kesehatan ibu maupun janin ${ }^{[6]}$.

Metode non-farmakologis (secara tradisional) sangat bervariasi yang dapat diterapkan untuk membantu mengurangi rasa nyeri, diantaranya adalah menggunakan massage/pijatan/ stimulasi kulit. Pijatan/massage memiliki prinsip mengurangi ketegangan, sehingga ibu akan merasa rileks dan nyaman menghadapi persalinan, metode ini dapat meningkatkan stamina dan tidak menyebabkan depresi pernafasan pada bayi yang dilahirkan ${ }^{[5]}$. Stimulasi kulit akan merangsang serat-serat berdiameter besar untuk menutup gerbang bagi serat-serat yang berdiameter kecil yang mengantarkan nyeri sehingga nyeri dapat dikurangi. Salah satu contoh penerapan stimulasi kulit dengan mengompres dingin pada area kulit. Hal ini dilakukan karena sifat analgetik pada kompres dingin yang menyebabkan impuls nyeri lebih sedikit yang dihantarkan ke otak $^{[4]}$.

Terapi massage/pijatan sebagai upaya untuk mengurangi rasa nyeri pada persalinan yaitu massage effleurage. Effleurage adalah bentuk pijatan dengan menggunakan telapak tangan yang dilakukan dengan tekanan lembut dari arah bawah menuju ke atas (jantung) dengan arah yang memutar beraturan serta dilakukan secara berulang. Adanya tekanan yang lembut, gerakan ini bertujuan sebagai relaksasi dan menghangatkan punggung dan abdomen pada ibu bersalin. ${ }^{[7]}$. Penerapan massage effleurage ini mampu mengurangi rasa nyeri, selain itu tidak menimbulkan dampak pada ibu ataupun bayi, hal ini justru mampu memberikan efek relaksasi sehingga rasa nyeri pada ibu dapat menurun. ${ }^{[8]}$.

Ibu bersalin yang dilakukan kompres dingin mengalami penurunan nyeri yang sebelumnya mengalami nyeri hebat setelah dilakukan kompres dingin menjadi nyeri sedang. Pengurangan nyeri ini terjadi karena kompres dingin yang membuat daerah sekitar pusat nyeri menjadi mati rasa, menurunkan ketegangan otot yang berguna untuk menghilangkan nyeri ${ }^{[9]}$.

Tujuan dari penelitian ini adalah untuk mengetahui perbedaan efektivitas massage effleurage dan kompres dingin terhadap nyeri persalinan kala I persalinan di puskesmas kabupaten pekalongan..

\section{Metode Penelitian}

Jenis penelitian ini adalah Quasi eksperiment dengan desain two group pretest dan posttest without control group. Populasi pada penelitian ini adalah ibu bersalin pada kala I fase aktif di kabupaten pekalongan, sample penelitian ini adalah ibu bersalin fase aktif yang memenuhi kriteria yaitu kooperatif, tidak dalam kondisi patologis. Data yang digunakan menggunakan data primer, menggunakan lembar observasi Numerical Scale Rating (NSR) pada sebelum dan setelah tindakan. Analisis yang dilakukan terhadap dua variabel yang diduga berhubungan atau berkolerasi. Pada penelitian ini, peneliti ingin membandingkan nyeri 
persalinan dengan variable bebasnya adalah massage effleurage dan kompres dingin, variable terikatnya adalah nyeri persalinan. Data yang terkumpul di klasifikasikan sesuai dengan masing-masing variabel kemudian diuji normalitasnya menggunakan shapiro wilk test (responden < 50).

Adapun hasil uji normalitas pada kelompok massage effleurage yaitu $0,126(>0,05)$ menunjukkan data normal sehingga untuk mengetahui perbedaan sebelum dan setelah intervensi menggunakan uji paired $t$ test. Sedangkan uji normalitas pada kelompok kompres dingin yaitu $0,001(, 0,05)$ diperoleh hasil data tidak normal, sehingga menggunakan uji wilcoxon. Pada hasil uji normalitas dua kelompok yaitu 0,002 $(0,05)$ didapatkan data tidak normal sehingga untuk mengetahui efektifitas massage effleurage dan kompres dingin terhadap nyeri persalinan menggunakan uji MannWhitney.

\section{Hasil dan Pembahasan}

Tabel 1. Distribusi nyeri persalinan sebelum dan setelah dilakukan massage effleurage

\begin{tabular}{lcccc}
\cline { 1 - 4 } $\begin{array}{l}\text { Nyeri } \\
\text { persalinan }\end{array}$ & \multicolumn{2}{c}{ Sebelum } & \multicolumn{2}{c}{ Setelah } \\
\cline { 1 - 4 } & F & \% & F & $\%$ \\
\cline { 1 - 4 } Ringan & 0 & 0 & 8 & 53,3 \\
sedang & 4 & 26,7 & 7 & 46,7 \\
berat & 11 & 73,3 & 0 & 0 \\
\hline Total & 15 & 100 & 1 & 100 \\
& & & 5 & \\
\hline
\end{tabular}

Tabel 1. menunjukkan nyeri persalinan pada responden sebelum dilakukan massage effleurage sebagian besar mengalami nyeri berat $(73,3 \%)$ dan setelah dilakukan massage effleurage, lebih dari separuh responden menunjukkan penurunan nyeri menjadi nyeri ringan $(53,3 \%)$ dan nyeri sedang $(46,7 \%)$.
Tabel 2. Distribusi nyeri persalinan sebelum dan setelah dilakukan Kompres dingin

\begin{tabular}{lcccc}
\hline $\begin{array}{l}\text { Nyeri } \\
\text { persalinan }\end{array}$ & \multicolumn{2}{c}{ Sebelum } & \multicolumn{2}{c}{ Setelah } \\
\cline { 1 - 5 } & F & \% & F & $\%$ \\
\hline Ringan & 0 & 0 & 3 & 20 \\
sedang & 4 & 26,7 & 10 & 66,7 \\
berat & 11 & 73,3 & 2 & 13,3 \\
\hline Total & 15 & 100 & 15 & 100 \\
\hline
\end{tabular}

Tabel 2. menunjukkan nyeri persalinan pada responden sebelum dilakukan massage effleurage sebagian besar mengalami nyeri berat (73,3\%). Setelah dilakukan kompres dingin $(20 \%)$ responden mengalami penurunan nyeri menjadi nyeri ringan, namun terdapat $(13,3 \%)$ responden yang masih tetap mengalami nyeri berat.

Tabel 3. Hasil analisa perbedaan nyeri persalinan sebelum dan setelah dilakukan massage effleurage

\begin{tabular}{|c|c|c|c|c|c|}
\hline \multirow{2}{*}{$\begin{array}{l}\text { Nyeri } \\
\text { persali } \\
\text { nan }\end{array}$} & \multirow[b]{2}{*}{ Mean } & \multirow{2}{*}{$\begin{array}{l}\text { Beda } \\
\text { mean }\end{array}$} & \multicolumn{2}{|c|}{$95 \%$ CI } & \multirow[b]{2}{*}{ Nilai p } \\
\hline & & & Lower & Upper & \\
\hline Sebelum & 7,60 & & & & \\
\hline Setelah & 3,60 & 4,00 & 3,31 & 4,69 & $<0,000$ \\
\hline
\end{tabular}

Tabel 3 didapatkan hasil bahwa nilai mean nyeri persalinan pada responden sebelum dilakukan massage effleurage adalah 7,60 dan nilai mean nyeri persalinan setelah dilakukan massage effleurage adalah 3,60. Dapat diketahui penurunan nilai rata-rata sebelum dan setelah dilakukan massage effleurage adalah 4,00. Hasil uji normalitas menggunakan Shapiro wilk (sampel $<50$ ) diperoleh distribusi data normal sehingga digunakan uji t berpasangan (paired t test). Hasil uji ppairet t test didapatkan nilai $\mathrm{p}<0,000(<0,05)$ hal ini berarti terdapat berbedaan nyeri persalinan antara sebelum dan setelah dilakukan massage effleurage pada ibu bersalin.

Munculnya rasa nyeri pada persalinan dimulai saat impuls nyeri yang berasal dari serviks dan korpus uteri, di hantarkan oleh serabut 
aferen melalui pleksus uteri, pleksus pelviks, pleksus hipogastrik inferior, middle, posterior dan masuk ke lumbal yang kemudian masuk ke spinal melalui lumbal 1, torakal 12, 11, dan 10. Massage effleurage yang diberikan melalui pijatan dengan tekanan lembut menyusuri segmen torakal 10 hingga sacrum mengeluarkan impuls pada saraf yang memiliki diameter besar yang banyak terdapat di kulit untuk memblok jalur korteks serebral $(\text { otak })^{[6]}$.

Adanya massage pada prinsipnya diberikan pada awal rasa nyeri atau sebelum impuls rasa sakit yang dibawa saraf yang berdiameter kecil ke otak. Pijatan dengan tehnik effleurage yang teratur dengan latihan peranafasan selama kontraksi, maka pijatan tersebut akan membuat relaksasi otot sehingga memberikan perasaan nyaman pada $\mathrm{ibu}^{[10]}$.

Penelitian lain yang mendukung penelitian ini menyebutkan bahwa sebagian besar ibu bersalin kala I fase aktif mengalami pengurangan nyeri, walaupun pengurangan skala nyeri ini masih bervariasi,bahkan masing-masing ada yang tidak berkurang skala nyerinya ${ }^{[11]}$. Tehnik massage ini merupakan salah satu manajemen nyeri yang dengan cara menekan secara lembut menggunkan telapak tangan, sehingga muncul interaksi yang mampu menguatkan antara mind, body and soul yang pada akhirnya berdampak relaksasi pada ibu bersalin ${ }^{[12]}$.

Penelitian lain yang memiliki hasil sejalan dengan penelitian ini didapatkan bahwa massage effleurage efektif untuk meredakan nyeri persalinan. Terjadinya penurunan intensitas nyeri persalinan karena adanya pemberian massage effleurage pada daerah punggung akan menyebabkan rangsangan pada serabut taktil kulit yang kemudian menghambat impuls nyeri dan hal ini menyebabkan korteks serebral tidak menerima impuls nyeri tersebut yang berdampak nyeri yang dirasakan mengalami penurunan ${ }^{[13]}$.

Tabel 4. Hasil analisa perbedaan nyeri persalinan sebelum dan setelah dilakukan kompres dingin

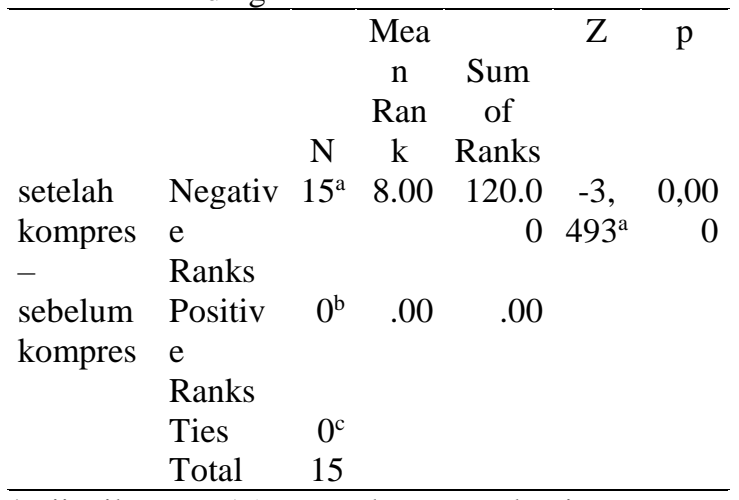

*Uji wilcoxon, 15 responden mengalami penurunan nyeri

Tabel 4. menunjukkan perbandingan nyeri persalinan sebelum dan setelah dilakukan kompres dingin. Hasil uji normalitas menggunakan Shapiro wilk (sampel $<50)$ diperoleh distribusi data tidak normal sehingga digunakan uji wilcoxon. Hasil uji wilcoxon didapatkan nilai p $0,000 \quad(<0,05)$ berarti ada perbedaan nyeri persalinan antara sebelum dan setelah dilakukan kompres dingin.

Penelitian yang sejalan dengan penelitian ini mendapatkan hasil bahwa ibu bersalin yang dilakukan kompres dingin mengalami penurunan nyeri yang sebelumnya mengalami nyeri hebat setelah dilakukan kompres dingin menjadi nyeri sedang ${ }^{[9]}$. Variasi nyeri yang dirasakan pada ibu dalam masa persalinan memiliki pengaruh yang bermakna antara stimulasi kulit dengan kompres menggunakan es terhadap intensitas nyeri yang dialami oleh ibu bersalin secara norma ${ }^{[14]}$.

Pengurangan nyeri ini terjadi karena kompres dingin yang membuat daerah sekitar pusat nyeri menjadi mati rasa, menurunkan ketegangan otot yang berguna untuk 
menghilangkan nyeri. Efek secara alamiah dari kompres dingin membuat otot saling menarik dan menguat, menyebabkan daerah sekitar kulit yang terkena es akan mati rasa, memblok aliran impuls nyeri dengan cara memperlambat hantaran syaraf menuju ke otak, memiliki efek anestesi secara lokal $^{[15]}$.

Hasil penelitian ini menunjukkan perbandingan nyeri persalinan sebelum dan setelah dilakukan kompres dingin. Dari 15 responden yang dilakukan intervensi kompres dingin, seluruh responden mengalami penurunan nyeri setelah dilakukan tindakan kompres dingin. Manajemen nyeri dengan tehnik relaksasi dikombinasikan dengan kompres dingin lebih efektif dibandingkan dengan teknik pernafasan saja selama persalinan terhadap penurunan nyeri ibu bersalin kala I fase aktif ${ }^{[16]}$.

Kerileksasian otot akan meningkat dengan pemberian kompres dingin. Kompres dingin akan membuat baal daerah yang terkena nyeri dengan memperlambat transmisi dan impuls-impuls lainnya melalui neuron-neuron sensorik (yang dapat membantu rasa kebal sebagai efek dari dingin). Kompres dingin juga dapat mengurangi pembengkakan dan menyejukkan bagi kulit ${ }^{[17]}$.

Tabel 5. Hasil analisa perbedaan nyeri persalinan sebelum dan setelah dilakukan kompres dingin

\begin{tabular}{|c|c|c|c|c|c|c|c|}
\hline $\begin{array}{l}\text { Inter } \\
\text { vensi }\end{array}$ & $\mathrm{N}$ & $\begin{array}{c}\text { Mea } \\
\mathrm{n} \\
\text { Ran } \\
\mathrm{k}\end{array}$ & $\begin{array}{c}\text { Sum } \\
\text { of } \\
\text { Rank } \\
\text { S }\end{array}$ & $\begin{array}{c}\text { Man } \\
\text { n- } \\
\text { Whit } \\
\text { ney } \\
\text { U }\end{array}$ & $\begin{array}{c}\text { Wilc } \\
\text { oxon } \\
\text { W }\end{array}$ & $\bar{Z}$ & $\mathrm{p}$ \\
\hline $\begin{array}{c}\text { Nyeri } \\
\text { mas } \\
\text { sage }\end{array}$ & 15 & $\begin{array}{c}20.8 \\
0\end{array}$ & $\begin{array}{c}312 . \\
00\end{array}$ & $\begin{array}{c}33.0 \\
00\end{array}$ & $\begin{array}{l}153 . \\
000\end{array}$ & $\begin{array}{c}- \\
3.4 \\
42\end{array}$ & 0.001 \\
\hline $\begin{array}{l}\text { Nyeri } \\
\text { kom } \\
\text { pres }\end{array}$ & 15 & $\begin{array}{c}10.2 \\
0\end{array}$ & $\begin{array}{c}153 . \\
00\end{array}$ & & & & \\
\hline Total & 30 & & & & & & \\
\hline
\end{tabular}

Tabel 5 menunjukkan hasil uji mann whitney didapatkan nilai $\mathrm{p}$ $0,001(<0,05)$ berarti ada perbedaan efektifitas massage effleurage dan kompres dingin terhadap nyeri persalinan. Dari hasil tersebut berarti tindakan massage effleurage lebih efektif dibandingkan dengan tindakan kompres dingin terhadap nyeri persalinan pada ibu bersalin kala I fase aktif. Hasil Uji coba terkontrol pada penelitian yang dilakukan di pada ibu bersalin di Iran memberikan bukti bahwa efek terapi pijat dapat mengurangi rasa nyeri persalinan khususnya pada wanita primipara ${ }^{[18]}$.

Penurunan nyeri persalinan dengan dilakukan massage effleurage $(20,80)$ lebih besar dibandingkan nyeri persalinan pada kelompok yang dilakukan kompres dingin $(10,20)$. Dari hasil tersebut berarti tindakan massage effleurage lebih efektif dibandingkan dengan tindakan kompres dingin terhadap nyeri persalinan pada ibu bersalin kala I fase aktif. Massage Effleurage dilakukan dengan menstimulasi kulit dengan cara memberikan tekanan lembut pada area permukaan kulit. Tindakan ini merupakan aplikasi dari teori gate control, yang akan lebih efektif dan maksimal hasilnya apabila dilakukan tanpa adanya penghalang seperti pakaian.

Kekuatan penekanan pada saat effleurage berbeda pada masingmasing ibu bersalin. Tindakan ini ini harus diupayakan secara beraturan agar ibu bersalin dapat mengatur pernafasannya dengan teratur. Massage ini juga dapat diaplikasikan pada area tubuh lain misalnya punggung tanpa melakukannya di daerah perut apabila ibu mengalami sensitivitas terhadap sentuhan yang akan mengakibatkan peningkatan intensitas kontraksi selama persalinan. Apabila ibu merasa tidak nyaman, tindakan ini juga perlu dihentikan. Sentuhan ringan yang salah satunya dengan cara massage 
effleurage mempunyai efek pengalihan serta mampu merangsang hormone endorfin untuk keluar hal ini akan merileksasi otot sehingga akan meningkatkan kenyamanan ibu yang mengalami nyeri persalinan ${ }^{[11]}$. Hormon endorfin yang dikeluarkan saat massage effleurage ini memiliki efek yang kuat, dapat mencapai 200 kali lebih kuat daripada morfin. Endorfin mempengaruhi transmisi implus yang diinterpretasikan sebagai nyeri yang bertugas sebagai neurotransmitter atau neuromodulator yang memiliki peran untuk memblok transmisi dari sinyal nyeri. Sehingga dengan adanya endorphin pada sinaps sel-sel saraf menyebabkan status penurunan dalam sensasi nyeri ${ }^{[17]}$.

Penolong persalinan khususnya untuk menangani kasus persalinan fisiologis harus mampu mengembangkan metode pengurang rasa nyeri secara non farmakologis. Hal ini diupayakan agar meningkatkan kemampuan ibu bersalin dalam memanage nyeri yang ia rasakan sehingga meminimalkan resiko terjadinya komplikasi lanjut akibat persalinan.

Massage effleurage memiliki pengaruh untuk menurunkan nyeri pada ibu bersalin di RSU PKU Delanggu Klaten, dengan nilai mean pre intervensi sebesar 5,11 (kategori nyeri sedang) dan post intervensi didapatkan nilai mean sebesar 2,00 (kategori nyeri ringan) ${ }^{[19]}$. Penelitian lain yang memperkuat hasil penelitian ini bahwa massage effleurage yang dilakukan selama kala I persalinan akan memperpendek kala I dan kala II persalinan $^{[20]}$.

\section{Kesimpulan}

Terdapat perbedaan nyeri persalinan antara sebelum dan setelah dilakukan massage effeluarage dengan uji statistik $\mathrm{t}$ berpasangan, diperoleh nilai p 0,000 $(<0,05)$. Terdapat perbedaan nyeri persalinan antara sebelum dan setelah dilakukan massage effleurage menggunakan uji wilcoxon, diperoleh nilai $\mathrm{p}<0,000$ $(<0,05)$. Pada uji Mann Whitney, diperoleh nilai p 0,001 $(<0,05) \mathrm{Hal}$ ini berarti terdapat efektifitas massage effleurage dan kompres dingin terhadap nyeri persalinan kala I persalinan. Massage effleurage lebih efektif untuk menurunkan nyeri persalinan dibanding tindakan kompres dingin pada ibu bersalin kala I fase aktif. Sehingga diharapkan ada sosialisasi dan penerapan metode ini sebagai alternatif mengurangi nyeri persalinan non farmakologi.

\section{Ucapan Terima Kasih}

LPPM STIKES Muhammadiyah Pekajangan, BAPPEDA Kabupaten pekalongan, Dinas Kesehatan Kabupaten pekalongan dan Puskesmas di Kabupaten Pekalongan.

\section{Daftar Pustaka}

[1] Kemenkes RI. Profil Kesehatan Indonesia tahun 2016. Jakarta: Kemenkes RI. 2017.

[2] Irianto, S. Proseding Kebijakan kesehatan dan perlibatan komunitas dalam menurunkan AKI/AKB di Indonesia. Jakarta : Pusat Kajian Wanita dan Gender. 2015.

[3] Afifah, D., Mulyono, B. dan Pujiati, N. Perbedaan Tingkat nyeri persalinan Kala I pada ibu bersalin Normal Primigravida dan Multigravida di RB Nur Hikmah desa Kuwaron Gubug Kabupaten Grobogan.

Jurnal

Kebidanan.1(1)

[4] Khusniyah. Z dan Rizqi. HD.. Efektifitas Stimulasi kulit dengan teknik kompres hangat dan dingin terhadap penurunan persepsi nyeri kala I fase aktif persalinan fisiologis. Jurnal Eduhealth. 2013;3(1) 
[5] Rejeki, S., Nurullita, U., Krestanti, R. Tingkat Nyeri pinggang kala I persalinan melalui teknik back-effleurage dan counter-pressure. Jurnal Keperawatan Maternitas. 2013; 1(2):124-133

[6] Maryunani, A. Nyeri dalam persalinan "teknik dan cara penanganannya. Jakarta : Trans info media. 2010.

[7] Parulian, TS., Sitompul, J., Oktrifiana, AN. Pengaruh teknik Effleurage massage terhadap perubahan nyeri pada ibu post partum di RS Saringgih Bandung. Jurnal Kesehatan "Caring and enthusiasm" STIKES Santo Borromeus. 2014;1(3)

[8] Wulandari, P dan Hiba PDN. Pengaruh Massage effleurage terhadap pengurangan tingkat nyeri persalinan kala I fase aktif pada primigravida di ruang bougenville RSUD Tugurejo Semarang. Jurnal Keperawatan Maternitas. 2015;3 (1): 59-67

[9] Turlina, L dan Ratnasari, NVE. Pengaruh kompres dingin terhadap penurunan Nyeri persalinan kala I fase aktif Di BPS Ny. Mujiyati kabupaten Lamongan. Jurnal Kebidanan dan Keperawatan. 2015;11 (2):143-150

[10] Maslikhanah. Penerapan tehnik pijat effleurage sebagai upaya penurunan nyeri persalinan pada ibu inpartu kala I fase aktif. Skripsi. UNS. 2011.

[11] Handayani Esti, Pramono Giri kiswoyo. Pengaruh masase punggung terhadap pengurangan nyeri persalinan kala I fase aktif pada ibu bersalin normal di BPM wilayah kerja puskesmas tegalrejo kabupaten Magelang. Politehnik kesehatan Kemenkes Semarang. 2012.
[12] Riet, P.V., Effleurage and Petrisage: Holistic practice in Thailand. Contemporary Nurse, 2011; 37 (2): 227-228.

[13] Utami, R.N. Perbedaan Efektivitas lama pemberian Rose Effleurage terhadap Intensitas nyeri Kala I fase aktif pada persalinan normal primigravida di kota semarang. Jurnal kebidanan. 2015; 2(4): 20-30

[14] Muniroh, S. Pengaruh stimulasi Kulit dengan teknik kompres menggunakan es terhadap penurunan persepsi nyeri kala I fase aktif persalinan fisiologis. Journal Eduhealth. 2013;3(1)

[15] Felina, M., Masrul., Iryani, D. Kompres panas dan dingin terhadap penurunan nyeri Kala I Fase Aktif Persalinan Fisiologis ibu primipara. Jurnal kesehatan Andalas. 2015; 4 (1): 58-64

[16] Suparni, Perbedaan Efektivitas Relaksasi dan Kompres Dingin Terhadap Intensitas Nyeri Persalinan Ibu Bersalin Kala I Fase Aktif (Studi Pada Ibu Bersalin di Kabupaten Pekalongan Tahun 2014). Tesis. Universitas Diponegoro. Semarang. 2014.

[17] Andarmoyo, SS. Persalinan tanpa nyeri berlebihan.Yogyakarta : ArRuzz media. 2013.

[18] Ranjbaran M, Khorsandi M, Matourypour P, Shamsi M. Effect of Massage Therapy on Labor Pain Reduction in Primiparous Women: A Systematic Review and Metaanalysis of Randomized Controlled Clinical Trials in Iran. Iranian Journal of Nursing and Midwifery Research. 2017; 22(4): 257261

[19] Wahyuni S dan Wahyuningsih, E. Pengaruh massage 
effleurage terhadap Tingkat nyeri persalinan kala I fase aktif pada ibu bersalin di RSU PKU Muhammadiyah Delanggu Klaten, Journal Involusi Kebidanan. 2015; 5(10) 43-53
[20] Haghighi, N.B.,Masoumi, S.Z.,\& Kazemi, F. Effect of Massage Therapy on Duration of labour : a. randomized Controlled Trial. Journal of Clinical and Diagnostic Research. 2016; 10(4): 12-15 